Author manuscript

\title{
Charting the Potential of Landscape Urbanism in Dubai
}

J ulian Bolleter

The Australian Urban Design Research Centre, The University of Western Australia, Perth, Australia

To cite this article: J ulian Bolleter (2015): Charting the Potential of Landscape Urbanism in Dubai, Landscape Research, DOI: 10.1080/01426397.2014.967189 


\title{
Charting the Potential of Landscape Urbanism in Dubai
}

\author{
JULIAN BOLLETER \\ The Australian Urban Design Research Centre, The University of Western Australia, Perth, Australia
}

\begin{abstract}
Landscape Urbanism has been, to date, a theory emerging primarily from the Western world. This paper counters the Western focus by exploring the potential of Landscape Urbanism theory in Dubai. In a previous article published by the author, landscape architecture in Dubai has been identified as diverging from the tenets of the various charters of the International Federation of Landscape Architects (IFLA), having apparently scant regard for pressing ecological, social and cultural design issues. Landscape Urbanism in this paper is discussed with respect to its ability to bolster the practice of landscape architecture in Dubai in relation to these issues. The paper argues that a number of key facets of Landscape Urbanism appear difficult to reconcile with the ecological, social and cultural conditions of Dubai. Further to this, it tends to lack the tools by which landscape urbanists in Dubai could link theory with practice.
\end{abstract}

KEY WoRDS: Landscape Urbanism, landscape architecture, Dubai

\section{Introduction}

Landscape Urbanism, to date, has been a theory that has emerged from the United States and to a lesser degree, Europe and Australia. In fact, most of the key authors who have been associated with the conversation regarding Landscape Urbanism hail from the nexus of the University of Pennsylvania and Harvard, which are considered by some as the "intellectual twin peaks of landscape architecture" (Thompson, 2011, p. 8).

Given Landscape Urbanism is entering its "middle age" (Waldheim, 2010), it is timely to ask how Landscape Urbanism theory may be applied in regions outside of North America (Thompson, 2011, p. 8), which are markedly different in morphological, social, cultural and ecological terms. Indeed, the specific conditions to which Landscape Urbanism first arose, that is, de-industrialisation and de-population of the city core (Thompson, 2011, p. 23), are in stark contrast to Dubai's largely non-existent industrial base and rapid population growth.

The application of Landscape Urbanism outside of North America has been initiated via the research of Kelly Shannon (2008), which focuses attention on urbanisation in the watery landscapes of Vietnam, the praxis of Landscape Urbanism theoretician James Corner via his commercial office Field Operations in Qianhai, 
China (Bull, Weller, \& Bolleter, 2013, p. 62), and to a degree via projects being conducted by students of the Architectural Association Landscape Urbanism programme (2013) in the Middle East and Asia. The author endeavours to further this process by exploring the potential of Landscape Urbanism to bolster the practice of landscape architectural practice in Dubai in the United Arab Emirates.

Dubai has been chosen as a case study because Landscape Urbanism is yet to be applied in either theoretical or practical terms in the Middle East. Also, Dubai is often the reference point by which the development of other Middle Eastern cities, particularly in the Arabian Gulf region, is charted-elements of Dubai's development either being copied or used as an example of what is to be avoided (Abaza, 2011). At a larger scale, Rem Koolhaas points to the Arabian Gulf itself as being the model for development in the region:

The Gulf is not just reconfiguring itself; it's reconfiguring the world. The Gulf's entrepreneurs are reaching places that modernity has not reached before ... Perhaps the most compelling reason to take the Gulf seriously is that its emerging model of the city is being multiplied in a vast zone of reduced architectural visibility that ranges from Morocco in the West, then via Turkey and Azerbaijan to China in the East. (Koolhaas, 2007, p. 7)

Further to this, gargantuan development companies, controlled by Dubai's rulers, such as Emaar and Dubai Holdings, are exporting "Dubai models" of urban development to China, Jordan, Tunisia, Morocco, Syria, Turkey, Egypt and Saudi Arabia, among others.

The author has argued in a previous paper that Dubai landscape architecture has diverged from IFLA's various charters concerning biodiversity protection, social equity and responsiveness to local culture (Bolleter, 2009, p. 28), and is arguably in a state of crisis. This crisis when replicated at the scale that Koolhaas refers is of serious concern. In the light of this situation, this paper will test the hypothesis that Landscape Urbanism theory can aid Dubai landscape architecture in dealing with the various ecological, social and cultural crises it faces. This hypothesis is activated by a research question:

What can Landscape Urbanism theory contribute to the practice of landscape architecture in Dubai so as to bolster its ethos of supporting biodiversity, social equity and integration, and responding to local culture?

The related sub research question for the paper is:

What strengths and weaknesses in Landscape Urbanism theory are revealed when it is applied to the practice of landscape architecture in Dubai?

Landscape Urbanism proponent James Corner claims that Landscape Urbanism offers some of the most compelling future directions for the "advancement of a more socially just, politically emancipating and ecologically sane mix of spatiotemporal production processes" in a world gone awry (Corner, 2003, p. 62). This paper will test the veracity of this claim in the Dubai context. 
The potential of Landscape Urbanism in this respect will be explored in relation to a number of key tenets of particular relevance to potentially bolstering landscape architecture's ethos of ecological sustainability, social equity and cultural responsiveness (Bolleter, 2009) in Dubai. The tenets to be explored in this paper are:

(1) Landscape Urbanism rejects the binary opposition between nature and culture (Thompson, 2011, p. 9) (or) Landscape Urbanism aims to directly engage the city as a hybrid ecology (Thompson, 2011; Weller, 2006b). This will be discussed in relation to its ability to bolster landscape architectural practice to support biodiversity in Dubai.

(2) Landscape Urbanism is less concerned with what things look like, and more with what they do (Thompson, 2011, p. 12). This will be discussed in relation to its ability to bolster landscape architectural practice to support social equity and integration in Dubai.

(3) Landscape Urbanism privileges an objective understanding of site forces, not the designer's subjectivity (Weller, 2006b, p. 67). This will be discussed in relation to its ability to bolster landscape architectural practice to be more responsive to local culture.

While Landscape Urbanism has other tenets these relate less directly to the ecological, social and cultural ethos of landscape architecture and hence, for the sake of brevity, have been omitted from this paper.

The paper will make reference to a number of terms that require clarification. "Orthodox landscape architecture" will be used to refer to the typical commercial practice of landscape architecture in the Western world in the late capitalist period. "Dubai landscape architecture" will be used to refer to the commercial practice of landscape architecture in Dubai by either landscape architectural companies based in Dubai or those from remote locations. A hypothetical landscape architect in Dubai aspiring to apply Landscape Urbanism theory to practice will be referred to as a Dubai landscape urbanist.

\section{Ecological Crisis}

Dubai is situated at the northern tip of the Rub al Khali Desert, a desert which covers about $600,000 \mathrm{~km}^{2}$ of Southern Arabia (Guba \& Glennie, 1998, p. 57). The city has been built over a coastal sabkha (salt marsh) which typically occurs in the intertidal areas between the Rub al Khali Desert and the Arabian Gulf to the west (Kurschner, 1998 , p. 64). Conceptions of what actually constitutes nature and culture, in Dubai's hyper-arid environment, tend to be confused. Indeed, the highly artificial landscape that typically swathes Dubai's developments, and forms the backdrop of the Dubai Municipality Park system, often is equated with nature despite it having almost no real ecological value (Doherty, 2008) (Figure 1). Described elsewhere by the author as ParaScape (2009), there is considerable academic and anecdotal evidence to suggest that the continuing deployment of this verdant landscape trades on a reading of "verdant landscape" as a symbolic recreation of the Islamic Paradise (Bolleter, 2009; Ouis, 2002, p. 339). The potency of the image of paradise in Islamic culture is, in part, due to the 


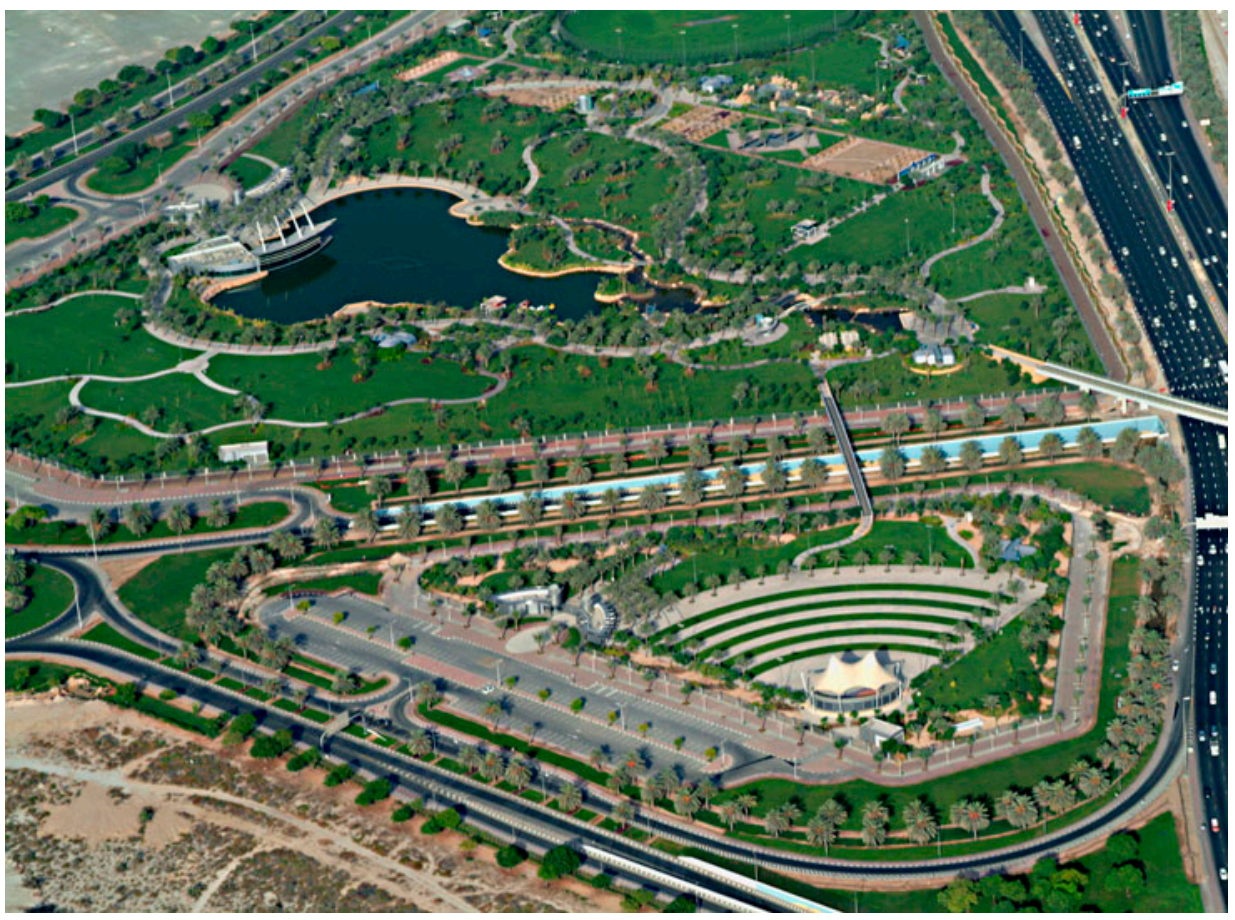

Figure 1. The lush, pastoral and highly artificial landscape of Zabeel Park. Photo courtesy of Cracknell Landscape Architecture.

fact that the descriptions of the garden of Paradise are held up as something not only to aspire to in the afterlife, but also as something to recreate here on earth (Brookes, 1987, p. 21). The resultant situation whereby green verdure becomes associated with paradise and henceforth is naturalised tends to typecast the desert and sabkha, Dubai's indigenous ecology, as a tabula rasa.

This conceptualisation appears to have been instrumental in the relative failure of McHargian ecological planning methods in Dubai. The Structure Plan for the Dubai Urban Area 1993-2012, was structured by an, albeit superficial, McHargian mapping of "important biological areas" requiring conservation (Parsons Harland Bartholomew, 1995). Despite this, rampant urban development in Dubai since 1993 has seen these areas partly destroyed (Figure 2). These important biological areas included terrestrial habitat in the form of "open desert woodland" which extends east of Dubai's urbanised area (Figure 3). This landscape contains species such as the desert hare, gazelles, oryx, foxes and falcons (David Gallacher, 2007). Other important biological areas identified included sabkha areas (Dubai Municipality, 2003).

The author has argued elsewhere that the partial destruction of these important biological areas is because these landscapes have not been assigned any value as natural systems due to their hyper-arid and sparsely vegetated nature (Bolleter, 2009, p. 37), and as such have provided little resistance to development. Aesthetically, the vast, hyper-arid Rub al Khali Desert and the desiccated salt-encrusted sands of coastal sabkha do not align automatically with a typical McHargian construction of wilderness 


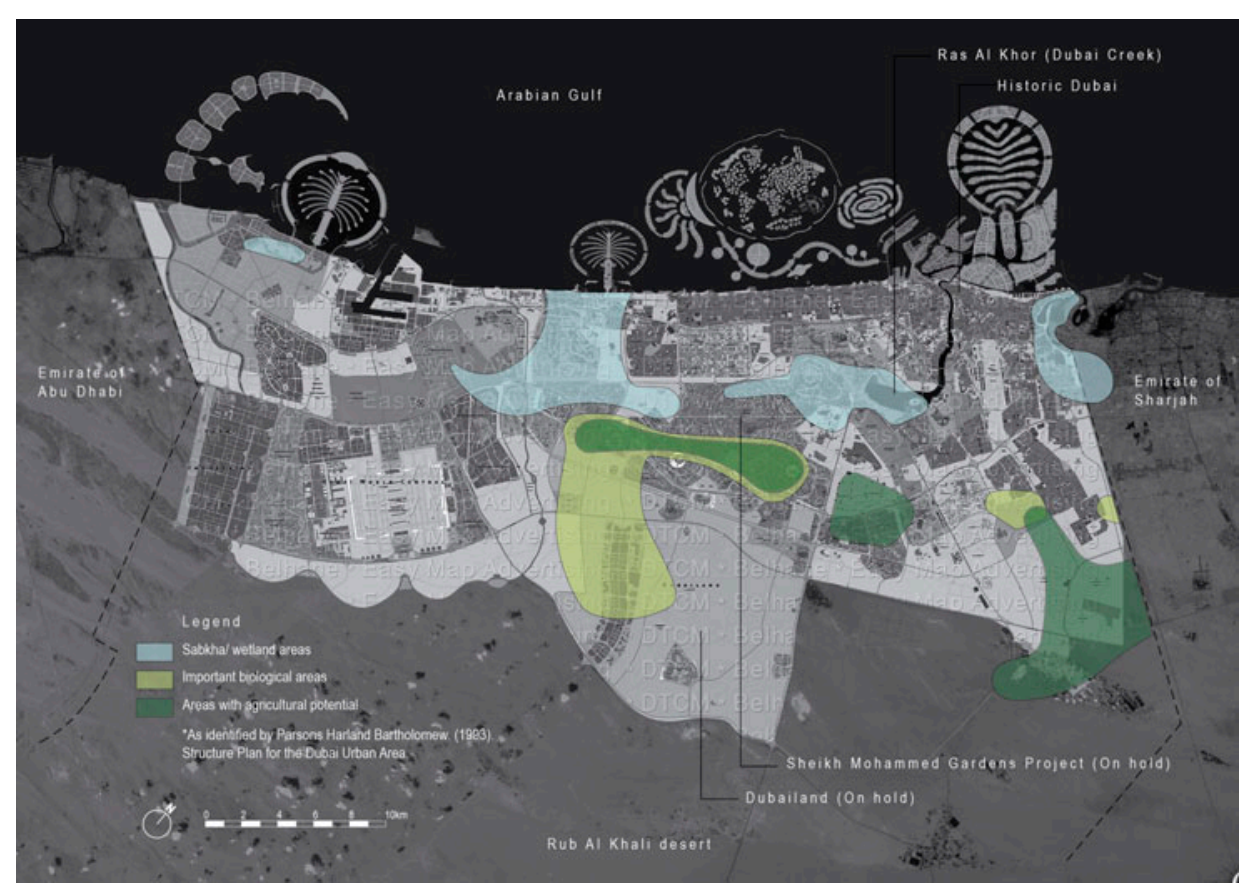

Figure 2. The important 'biological zones' identified by Parsons Harland Bartholomew in 1993 have been significantly affected by development.

as nature. Indeed, desert landscapes of the Arabian Peninsula have been associated historically with savagery, hardships and deprivations and the ecological value of these landscapes is not immediately apparent to the untrained eye.

\section{The Potential of Landscape Urbanism to Support Biodiversity in Dubai}

\section{The Landscape Urbanism City}

The shift in perception of the city as constituting landscape (Office for Metropolitan Architecture, Koolhaas, \& Mau, 1995, p. 835), which underpins Landscape Urbanism's claims for an expanded sphere of influence, reflects the changing nature of cities over the course of the twentieth century. The city model, of which Landscape Urbanism theory is a product, is typically that of a first-world, late twentieth, early twenty-first century global metropolis in which the "traditional notion of the city ... has been largely replaced by a more polycentric and weblike sprawl" (Wall, 1999, p. 234).

It is in this context that, it is argued, traditional binary notions of a city and its landscape can be reconceptualised and engaged as a form of "hybridised chaotic ecology"1 (Weller, 2008, p. 248). While Landscape Urbanism theory identifies a blurring of the traditional binary coupling of a city and its landscape, it also entails a collapse of the grand, polarised narratives of nature and culture implied by McHarg's environmental planning practice (Thompson, 2011, p. 9; Waldheim, 2002, p. 12) and modernity in general. 


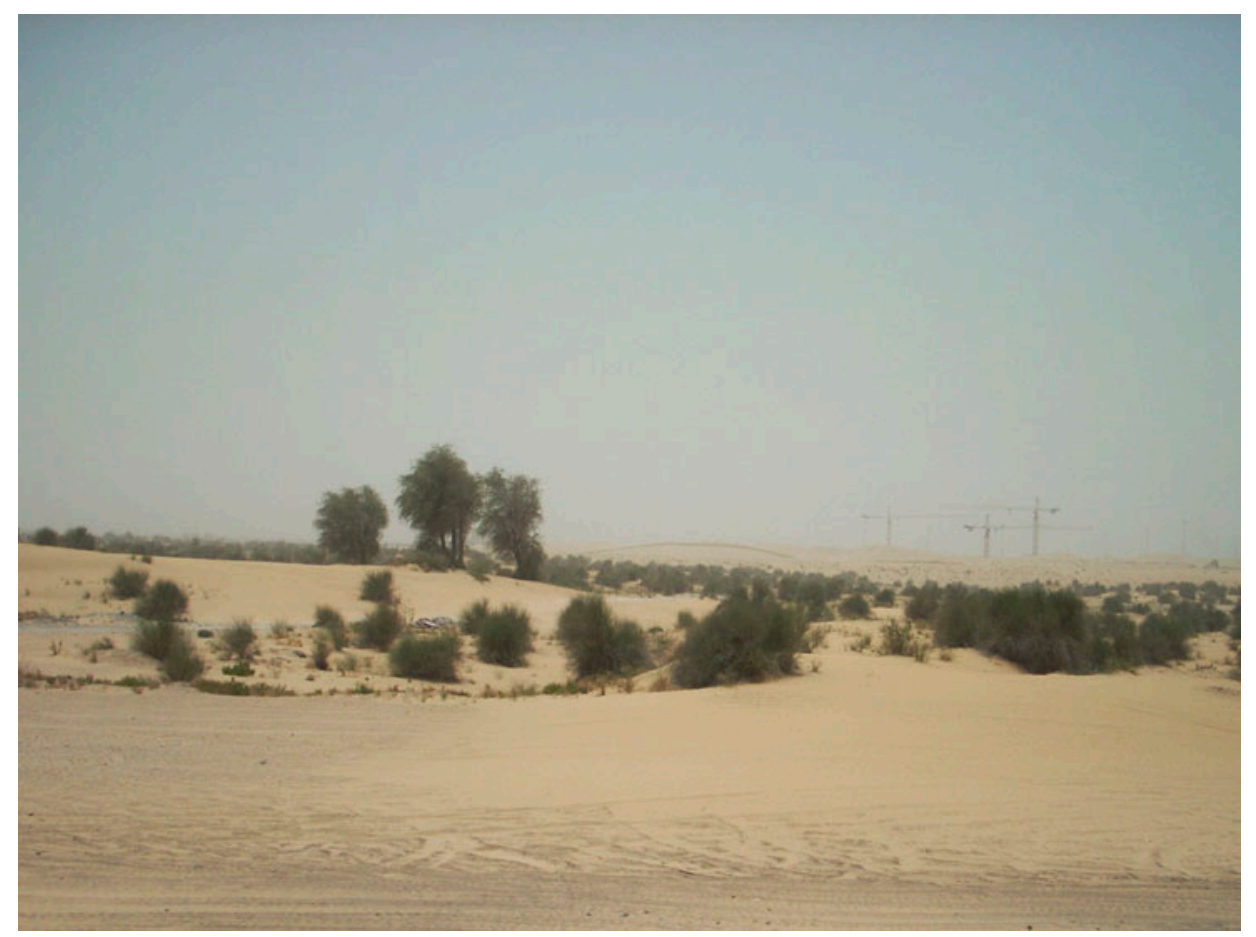

Figure 3. Sparsely vegetated Ghaf woodland on Dubai's desert fringes.

The problem that Landscape Urbanism theory identifies with a binary coupling of nature and culture is that landscape architecture tends as a result to be relegated to being the passive, subjugated part (Weller, 2006b, p. 67). Further to this the notion of fixed physical boundaries between "natural" wilderness areas and "cultural" urban areas is regarded as being ultimately detrimental in ecological terms. Contemporary ecological science relies on a more complex understanding of a given site as being part of an expanded system that receives and provides matter, energy and organisms both to and from nearby, as well as remote locations (Pulliam \& Johnson, 2002, p. 54).

\section{The Potential of a Model of the City as Hybridised Ecology in Dubai}

Landscape Urbanism's model of "hybridised ecology" (Weller, 2008, p. 248) can be considered both in relation to its potential to aid in the conservation of remnant biodiversity, and for the potential creation of new "hybridised" ecological systems. Certainly in Dubai its greatest potential would seem to relate to the latter. As Weller describes, "In a model where nature and culture are hybridised, and nature is not an absolute to be protected, landscape architecture is potentially able to develop a more creative relationship with ecology" (Weller, 2007). This shift from conservation to creative proposition would appear to have significance in Dubai given that many of the 
important biological areas within Dubai's metropolitan area have been significantly affected by development (Bolleter, 2009, p. 37). As such, these areas arguably now need to be reconstructed, not reserved.

However, the problem for a landscape urbanist in Dubai keen to pursue a model of "hybridised ecology" is what this ecology actually is. Certainly Corner's evocative but ambiguous descriptions of the "lyrical play between nectar and Nutrasweet, between birdsong and Beastie Boys, between the springtime flood surge and drip of tap water, between mossy heaths and hot asphaltic surfaces..." (Corner, 2006) do not provide much in the way of direct guidance for the practitioner. For some Landscape Urbanism projects, the hybridising of natural and cultural systems amounts to the structuring of urban areas in relation to hydrological systems. This tendency can be seen in James Corner Field Operations" "Quinhai Water City" project (Bull et al., 2013), Richard Weller's "Wungong Urban Water" project (Weller, 2008) reflecting what critics of Landscape Urbanism refer to as the "hydrological privilege" (Duany \& Talen, 2013, p. 7). While Dubai does experience flooding this is largely due to drains filling up with sand in the extended periods between significant rainfall events. This aside, given Dubai's extremely arid climate hydrology cannot be the stand in for "nature" in a model of hybridised ecology. In contrast to the temperate climes from which Landscape Urbanism theory emerged, natural systems of vegetation in Dubai are also very sparse and are not easily interwoven with urban development as a hybridised ecology city model would seem to propose. To put this in perspective, in the Al Maha desert reserve which is loosely comparable with natural conditions, indigenous gazelles and oryx occur at the very low densities with one animal per 13 Hectares and 11 Hectares, respectively (Gallacher \& Hill, 2007, p. 856). Given this scarcity of both fauna and flora, it is difficult to picture how Dubai's desert landscape could be hybridised with an urban setting - the desert landscape requiring such broad areas to contain a significant diversity and richness of species. This question of course goes to ecological science, a field which is poorly developed in Dubai. As ecologist Dr. Mike Wells answered regarding a query about sourcing literature on designing in relation to Dubai's fragile ecology, "There is not much published on this if anything specific to the Middle Eastand the book needs writing" (Wells, 2008).

Landscape Urbanism proponents such as Richard Weller concedes the difficulty of this process of hybridisation:

In practice it is hard to reconcile the land's ecological systems with suburban (or urban) systems. The reason for this is fundamental; ecological systems are organic and boundless whereas suburban systems are mechanistic; ecological systems are radically site specific whereas suburban systems are standardised and generic. (Weller, 2008, p. 254)

This challenge, which is not insignificant in more temperate climes, becomes particularly difficult in Dubai where the natural systems are not heavily vegetated or "wet" enough to provide enough resistance to structure urban form.

Of course a "negotiated" landscape, which synthesises the hyper-arid desert landscape and the verdant artificiality of Para-Scape, could be more closely entwined with Dubai's urban form as per a model of "hybrid ecology". However, this negotiated 
landscape is unlikely to support local biodiversity, reflecting the difficulty of organisms trading one habitat for another (Marsh, 2005, p. 380). Unlike humans, who have a wide range of habitat versatility, most organisms displaced from one habitat cannot simply take up life in another (Marsh, 2005, p. 380). This is certainly the case in Dubai where many of verdant green spaces have little biodiversity value because they actively conflict with indigenous ecosystems, disrupting the native desert habitats with foreign and ecologically sterile species (Doherty, 2008, p. 106). While the idea of the design of urban districts in relation to low biodiversity greenspace is not in itself problematic it would appear to run counter to Landscape Urbanism's proposition that the horizontal flows and dynamic processes of ecology should inform "the design of large-scale urban settings" (Yang, 2013, p. 265).

Landscape Urbanism's model of "hybridised ecology" is also potentially problematic for a Dubai landscape urbanist trying to employ it to structure an argument for the protection of existing biodiversity. Weller quite rightly worries that by "forsaking pure nature as a site of resistance" Landscape Urbanism is in turn prone to "complicity" in the destruction of natural areas (Weller, 2006b, p. 67). Indeed, Landscape Urbanism's "naturalisation of the contemporary city" is concerning because it "confers a certain inevitability upon its growth, which in turn can seem to justify its rampant and destructive spread" (Weller, 2008, p. 249). The proposition of "hybridised ecology" as a means of protecting remnant ecologies in the Dubai context, where massive amounts of liquid capital is turned almost instantly into high value concrete property (Basar, 2007b) seems dangerous to say the least. If historically the clear spatial delineation of McHargian planning was not able to protect "important biological areas" from Dubai's deregulated development industry, then it is doubtful whether blurred conceptions of nature and culture will prevent further transgressions. While Landscape Urbanism theory, by extension, may identify a clearly delineated edge between Dubai's "nature" and "culture" as not adequately defining its true complexity, openness and unpredictability of ecological relationships, it at least provides a landscape urbanist in Dubai a persuasive tool to engage with the development industry and rulers.

While the notion of a "hybridised ecology" model is problematic in purely landscape terms, the presumption in Landscape Urbanism theory is that the hybridised ecology city model would also provide design clues about the design of urbanism and infrastructure. Indeed, Landscape Urbanism claims that landscape is the primary element of urban order (Waldheim, 2002, p. 14) and that Landscape Urbanism includes within the "purview of design all that is in the landscape- infrastructure and buildings" (Weller, 2006b, p. 67). But how does Dubai's indigenous desert landscape direct a landscape urbanist in terms of the design of buildings or infrastructure? While arguably the overall composition of urban districts should be responsive to Dubai's subtle shifts in topography and sparse existing vegetation, this process is more about telling the designer where you should not build, not what you actually should build; and is in this sense McHargian. Thus, the aspiring landscape urbanist in Dubai must resort to the traditional determinants of urban form such as climate, economics, culture, etc. This in itself is not necessarily problematic; it is just the usefulness of the indigenous landscape in generating urban form is marginal at best. ${ }^{2}$ Thus, while Landscape Urbanism claims the city and its landscapes as "hybrid ecology", and thus part of its disciplinary territory, Landscape Urbanism does not necessarily provide the discipline specific tools by which an aspiring Dubai landscape urbanist can engage with the design of urbanism or infrastructure. 
The "hybridised ecology" city model proposed by Landscape Urbanism also reflects openness and unpredictability of ecological systems in time (Weller, 2008, p. 249); ecology being the model from which Landscape Urbanism's principles of "indeterminacy and open-endedness" emerge (Corner, 2003, p. 59) . Again, while this may reflect the true nature of ecological systems, it sits in contrast to the actual practice of development in Dubai. As Basar describes the ruling tribal family believe the "minds of a select few should map national visions for the many. Once decided upon, plans for the future are mobilised almost instantly into direct action" (Basar, 2007a, p. 92). It is within this context that a landscape urbanist in Dubai would struggle to articulate to clients why aspects of landscape and urban design need to be open-ended and indeterminate, this being precisely what Dubai clients typically do not want. In Dubai's real estate environment developers rather aspire to a "finished" marketable image for their development.

In conclusion it would appear that Landscape Urbanism's model of the city as "hybridised chaotic ecology" (Weller, 2008, p. 248) appears to offer little to the landscape urbanist in Dubai working towards fulfilling IFLA's ethos of supporting environmental protection and biodiversity (International Federation of Landscape Architects). It would appear poorly adapted to the incredibly sparse and fragile desert and sabkha ecologies which are not easily entwined with urban development. It is also not well suited to Dubai's typically unregulated development industry which would be quick to exploit or dismiss the spatial and temporal ambiguities of Landscape Urbanism's model of "hybridised ecology". Finally, it is not clear that the "hybridised ecology" model is indeed that different, or better, than any good current landscape architectural/landscape planning practice that reconciles approaches from conservation biology, restoration ecology (Johnson \& Hill, 2002), with sustainable and aesthetically pleasing goals.

\section{Social Crisis}

\section{Dubai's Socio-Political Structure}

The dominant economic system in Dubai is one of neo-liberalism. Social geographer David Harvey describes the aspiration of the neo-liberal state as being to manufacture a "good business climate" and thus to "optimise conditions for capital accumulation no matter what the consequences for employment or social well-being" (Harvey, 2005, p. 25). Indeed, Dubai has achieved what "neo liberal reactionaries only dream of; a paradise of free enterprise without income taxes, trade unions or opposition parties" (Davis, 2007, p. 67).

Dubai's extreme socio-economic stratification belies the fact that while Dubai is extremely multicultural, little interaction occurs between the strata of society. In this regard, Dubai has successfully created spaces for diverging cultural groups without requiring significant assimilation (Kirchner \& Rab, 2007, p. 18). The separation of ethnic groups along economic lines while allowing for a "functioning" multicultural society, also creates conditions in which segments of the society become "othered" when viewed from the perspective of the dominant strata of Dubai society. The "other" in Dubai terms invariably becomes associated with the generally unskilled immigrant Asian labourer who is housed in accommodation camps away from the city and who 
typically earns 1/16th of the wage of the typical Dubai resident (Mafiwasta, 2007). The "othering" of the labourer is also related to the fact they are primarily male. The labourer thus becomes, in part, a symbol of threat to the womenfolk and thus requires separation from the city.

\section{Detachment and Estrangement in Dubai's Scenography}

Dubai's extreme socio-economic stratification is also mirrored in Dubai's designed landscapes; for Dubai's unskilled migrant labourers much of the highly privatised city is not available to them. Even the "public" park system established by Dubai Municipality presently accounts for only $1 \%$ of Dubai's present urban area and can also only be considered semi-public as it is gated and an entry fee is charged.

Additionally, much of what constitutes public landscape, outside of the park system, is designed as scenography and is not intended to be used. Approximately, $77 \%$ of greenspace in Dubai is SLOIP (Space left over in planning) and only 23\% of greenspace constitutes Dubai Municipality parks which have a degree of functional programming (Dubai Municipality, 2004). Thus, the majority of "public" designed landscapes in Dubai are scenic and do not support any specific programmatic function. The deployment of Para-Scape, in this respect, perpetuates various claims to power in Dubai. Para-Scape is employed to legitimise the power of the ruling dynasty (Ouis, 2002). Despite significant efforts towards modernisation in other arenas, Dubai is still an autocracy where any evidence of true democracy proves difficult to find (Davidson, 2008, p. 137). This situation has been maintained by Dubai's rulers through what Davidson refers to as the "ruling bargain" (2008, p. 138). This ruling bargain exists between Dubai's rulers and national population and involves the buying of the populace's loyalty with distributed oil revenue and the "careful exploitation of a range of ideological, religious, and cultural resources" (Davidson, 2008, p. 138). Para-Scape, with its symbolic paradisiacal associations, becomes particularly effective as a tool for reinforcing this "ruling bargain". As Jonathon Smith attests the seductive appeal of "judiciously styled" visual landscape "may forestall reflection on the failure of society to furnish its members with the means to consume landscapes in more practical [and equitable] ways" (In Corner, 1999, p. 157). Dubai landscape architecture, in relation to this deception, often becomes an unwitting tool of the prevailing political and economic powerbrokers (Ouis, 2002).

\section{The Potential of Landscape Urbanism to Support Social Equity and Integration in Dubai}

\section{Landscape Urbanism and a "Utopia of Process"}

While the charters of Congress for the New Urbanism (2007) would appear to advocate form as being a mechanism through which a particular society can be engaged for positive ends, landscape urbanist James Corner turns to geographer David Harvey's proposition that what is required is a "utopia of process" not a "utopia of form" (Harvey, 2005, p. 25). It is this shift from "form" to "economic, socio-political, and ecological process" (Thompson, 2011, p. 6) that potentially underpins Landscape Urbanism's claims to actively engage societal structures to achieve Landscape Urbanism's socio-ecologically enriching ends (Lootsma, 1999, p. 273). 
The discussion of process in Landscape Urbanism literature occurs in relation to two different contexts. Firstly, it is advocated that Landscape Urbanism should focus attention on process within the larger social, political and economic contexts, and on the other hand that designed spaces should be more infrastructural and process orientated and less form driven (Corner, 1999, p. 160). This paper will discuss the potential of these two manifestations of Landscape Urbanism's "utopia of process" in relation to its potential to support Dubai landscape architecture to promote social equity and integration.

\section{The Potential of a "Utopia of Process" in Dubai}

Through a focus on process Landscape Urbanism seeks to engage with "uncontrolled capital accumulation" and "gross inqualities of politcal- economic power" (Harvey in Corner, 2006, p. 28), underlying forces that to a large degree have generated the physical shell of Dubai. It is this "utopia of process", "how things work in space and time" (Corner, 2006, p. 29), that Landscape Urbanism uses to distinguish itself from competing disciplines such as "new urbanism". Both Landscape Urbanism, and a number of significant urban design and planning theorists (Fainstein, 2003; Fishman, 2003), criticise new urbanism for its "easy elision of physical form with social condition", a situation in which new urbanism is seen to display "little theoretical rigour" (Fainstein, 2003, p. 182).

While New Urbanism is criticised for its tendency to create "utopias of spatial form" (Harvey, 2002, p. 156) rather than delineating the method of achieving them, social geographer David Harvey, who is often quoted in Landscape Urbanism literature (Corner, 2003, p. 62; Waldheim \& Berger, 2008), identifies the task as being to bring together a "spatiotemporal utopianism" which he describes as a "Utopia of process" (Harvey, 2002, p. 196). Unfortunately the exact processes which a landscape urbanist in Dubai should engage in remain ambiguous in Landscape Urbanism literature. Harvey's argument, cited by Corner, is that deregulation, globalisation, environmental protection, codes and regulations, market trends and so on are much more significant for the shaping of urban relationships than are spatial forms per se (Corner, 2003, p. 61). By extension what Corner seems to be saying is that landscape urbanists in Dubai could combat social inequality more effectively if they directly engaged the development industry or government, so as to have greater influence over the economic and regulatory settings that influence the resultant form of a city like Dubai.

In essence, this figure of the landscape urbanist in Dubai is a lobbyist for social equity and integration with Dubai's power brokers. While landscape architects in Dubai have relied on Dubai's rulers to legislate for public open space with disappointing results, a landscape urbanist could potentially engage with clients to find models for public space that are potentially both profitable and socially equitable. While Landscape Urbanism literature cites no particular examples in this respect, perhaps Olmsted's meticulous justification of the costs of Manhattan's Central Park in terms of the capitalisation of the parks value to proximate homeowners provides one such example (Crompton, 2005, p. 218). This however raises the question as to whether Landscape Urbanism's attention to process is not already embedded in a socially conscious practice of landscape architecture; Olmsted indeed being the father of the landscape architectural profession in the USA. 
The difficulty of a landscape urbanist in Dubai attempting such an engagement with the city's political and economic powerbrokers would be significant. The United Arab Emirates' ruling tribal family who control both government regulation and the development industry "believe the minds of a select few should map national visions for the many" (Basar, 2007a, p. 92). The ability of a Dubai landscape urbanist to be able to carry sway within this extremely closed and hierarchical socio-political structure is difficult to imagine.

Beyond lobbying for public space, social equity and integration from a broader perspective can be seen to encapsulate many issues such as housing segregation and affordability, access to public transport, and schools, to name a few. The issue for a landscape urbanist in Dubai seeking to broaden their sphere of influence to include "all that is in the landscape- infrastructure and buildings" (Weller, 2006b, p. 67) is that Landscape Urbanism theory has very little to say about pragmatic social equity issues such as "housing segregation ... pollution, concentrated poverty, traffic congestion, bad schools, affordability, safety, accessibility" the "issues form-based urban designers ... have been toiling with" (Talen, 2013, p. 112). Certainly, critics of Landscape Urbanism see its predilections for indeterminacy and process, and its overt ecological focus as a way of "forestalling the need to deal with such clichéd social concerns" (Talen, 2013, p. 112). While a landscape urbanist in Dubai may be able to navigate this complex terrain, the body of Landscape Urbanism literature certainly does not provide much direct practical or theoretical assistance.

Programmed landscape. Landscape Urbanism's focus on process is also proposed to occur in the design of landscapes. Here, the emphasis shifts from what things look like to how they work and what they do (Corner, 2003, p. 61). As Alex Wall describes "the goal of designing the urban surface is to increase its capacity to support and diversify activities in time..." (Wall, 1999, p. 233). A precursor to Landscape Urbanism's conceptual shift between scenographic and programmatic landscape is OMA's secondplace entry for the Parc De La Villette competition in Paris, France in 1982; a scheme which appears frequently in landscape urbanist literature (Waldheim, 2002, 2006; Wall, 1999; Weller, 2006a). The project's designers Rem Koolhaas and Bruce Mau describe the conventional park as a "replica of nature serviced by a minimal number of facilities that ensure its enjoyment" (1995, p. 921). The alternative to this approach, which is encapsulated in their Parc de la Villette design, is the orchestration of:

... the most dynamic coexistence of activities $\mathrm{x}, \mathrm{y}$, and $\mathrm{z}$ and to generate through their mutual interference a chain reaction of new, unprecedented events; or how to design a social condenser, based on horizontal congestion, the size of a park. (Office for Metropolitan Architecture et al., p. 921)

Central to the notion of the "social condenser" to which Koolhaas and Mau refer is the idea that design has the ability to affect social behaviour, the purpose of social condensers being to break down social hierarchies. This concept, derived from Russian constructivist theory, found expression in OMA's La Villette proposition in the creation of intersections between varied constituencies. In literal terms, this manifests itself as a 
series of physical striations, each containing particular park functions - the idea being that social friction and exchange will occur on the edges between these bands.

The rejection of stylised nature in favour of programmed landscape, similar to OMA's La Villette, becomes a central theme in Landscape Urbanism literature (Corner, 1999; Wall, 1999). Of course, while some Landscape Urbanism literature would appear to suggest otherwise, heavily programmed landscapes such as OMA's proposal for La Villette are also stylised; they are just not naturalistic aesthetics (Thompson, 2011, p. 12).

\section{The Potential of Landschaft in Dubai}

Significantly, if Para-Scape can be employed to promote particular socio political agendas to a populace (Bolleter, 2009), then presumably alternatively designed public landscapes could perhaps communicate more enriching and inclusive narratives to Dubai's society. In this respect Corner identifies the potential of "Landschaft". In Corner's writing, Landschaft is a German word that refers not to scenery but to the environment of a working community (Corner, 1999, p. 154). ${ }^{3}$ In the contemporary context, Corner considers Landschaft to constitute a landscape that is occupied, programmed, and not preoccupied with the creation of a fixed scene with a correspondingly fixed agenda (Corner, 1999). Following on from Corner's logic, the deployment of highly programmed, interactive and inclusive landscape in Dubai could have the potential to counter the symbolic fixity offered by Dubai's scenographic landscapes. As Wall explains about the work of landscape architect Adrian Geuze which he aligns with Landschaft "it is about making things and places that are indeterminate in their functions and thereby allow their users to invent and claim space for themselves" (Wall, 1999, p. 245).

The shift from stylistic, unprogrammed landscapes to Landschaft is regarded by proponents as one mechanism by which Landscape Urbanism can transform landscape from being "a product of culture to landscape as an agent producing and enriching culture" (Corner, 1999, p. 4).

\section{Contradictions between Landschaft and Dubai's Existing Parks}

It is important to acknowledge that Landscape Urbanism's predilection for highly programmed, indeterminate and inclusive landscapes sits in complete opposition to Dubai's existing parks which are highly scenographic, pastoral, largely un-programmed and semi-private. While the existing Dubai Municipality parks are described as being for "everyone", they are primarily intended as family areas for locals and wealthier expatriates (Figure 4).

Landscape Urbanism's model of Landschaft, and its attendant aim to erode social hierarchies raises particular issues when applied to the restrictive social context of Dubai. Whereas in the west, the privatisation of public space is considered to amount to a reduction in "civil liberties and freedom of expression", privatisation in Dubai often actually brings forth an expanded area of relative freedom for female Emiratis. Within the "confines of spaces owned by respectable Emirati families and corporations where gates, guards and camera surveillance are seen", the permissible space where a woman 


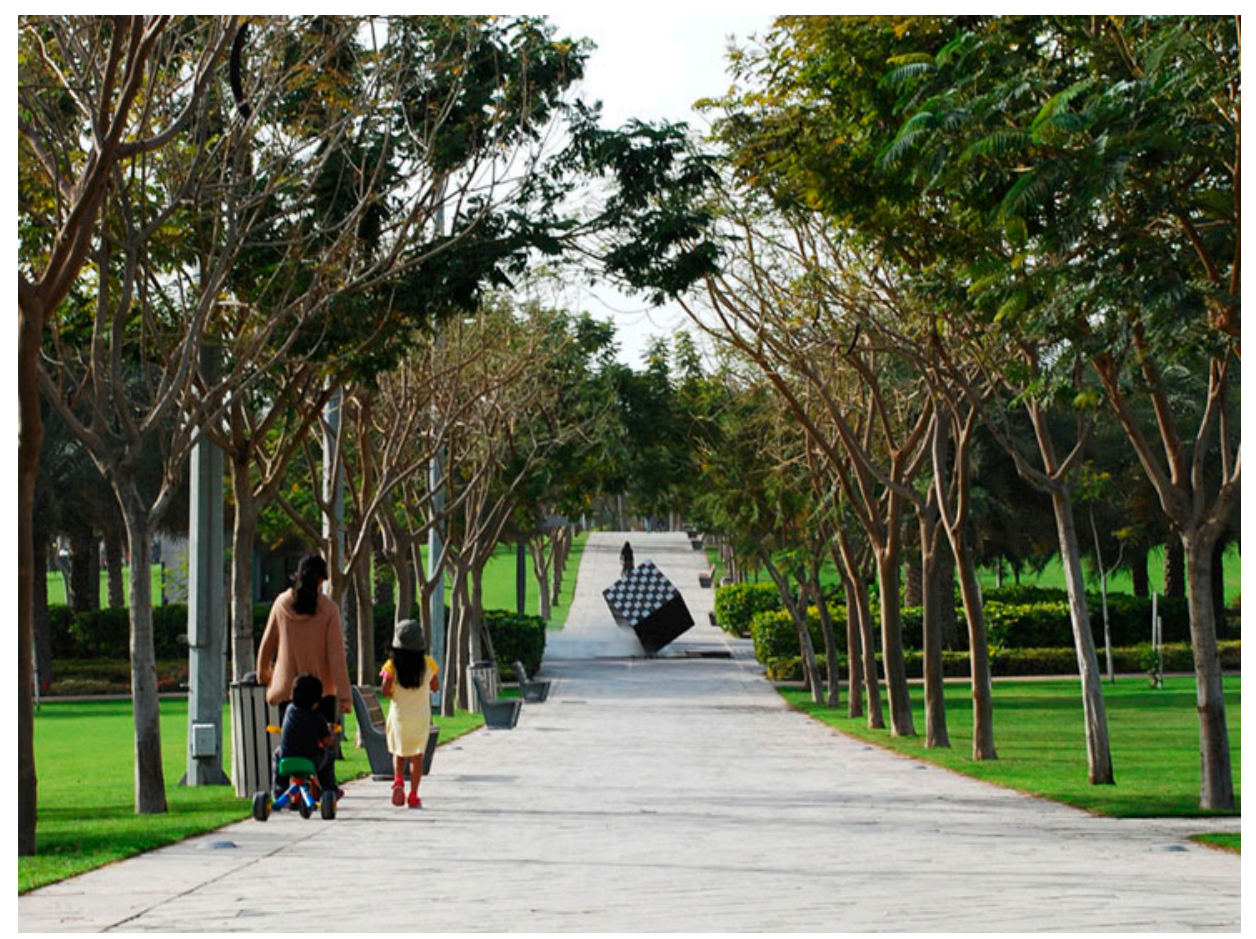

Figure 4. Dubai Municipality parks are principally family areas.

Image courtesy of Ed Maglente.

can move unveiled is extended (Andraos, 2007, p. 53). The fact that greater freedoms are often enjoyed by Islamic women in semi-private, as opposed to public space, is an irony that could be easily overlooked by a landscape urbanist on a quest for public space which erodes social hierarchies. A similar situation occurs at a larger scale in which cultural groups in Dubai "maintain strict segregatory measures, by having their own set of institutions which enable them to maintain their cultural values" (Elsheshtawy, 2004, p. 172). It is within this context that Landscape Urbanism's models of Landschaft as a social condenser aiming to break down social hierarchies, while perhaps admirable, appear problematic. While Dubai's heavily segregated society indeed requires more Landschaft spaces which allow for the interaction of various cultural groups, this interaction needs to be handled with care so that complex cultural sensitivities are respected. Landscape Urbanism's discussion of Landschaft, perhaps reflecting the author's origins, provides little guidance as to a more nuanced application of Landschaft in the cross-cultural context.

A further issue that arises in the deployment of Landschaft in Dubai and indeed in OMA's unbuilt Landschaft scheme for La Villette, which Alex Wall (1999) aligns with Landschaft, is the question of what this programmed Landschaft actually is. While Koolhaas and Mau refer to La Villette as a "landscape of social instruments", the actual programming remains ambiguous. In the accompanying text for their competition entry Koolhaas and Mau only specifically identify a limited number of what are actually 
traditional park functions: kiosks, playgrounds, sales kiosks, refreshment bars, picnic areas, amphitheatres, seating, chess tables, tribunes, puppet theatres, rollerskating surfaces and greenhouses (1995, pp. 925, 927). The question remains, in relation to both OMA's La Villette and Landschaft in Dubai, as to whether this limited amount of programming could really constitute the "engine of the project" that Wall says it is (Wall, 1999, p. 237). A study of recreational activities in Dubai reveals that recreation is often driven indoors by exceedingly hot temperatures and presumably Dubai's restrictive culture (Dubai Municipality, 2001). If this data is taken as a guide there remain precious few outdoor recreational activities that could be employed by a landscape architect in Dubai to successfully activate Landschaft in Dubai (Figures 5).

Despite its attendant problems and challenges Landscape Urbanism's "utopia of process" whether applied to the conceptualisation of a landscape urbanist's role in a given project, or to the design of public landscapes in Dubai seems to have some potential. For landscape architects to be more involved in the process behind the eventual formal resolution of urban areas of course seems timely, also a greater level of functionality in Dubai's overtly stylistic landscapes which invites usage and interaction, with more malleable symbolism, also seems timely. Whether these comparatively minor moves by Dubai landscape urbanists could achieve Harvey's "advancement of a more socially just, politically emancipating and ecologically sane mix of spatiotemporal

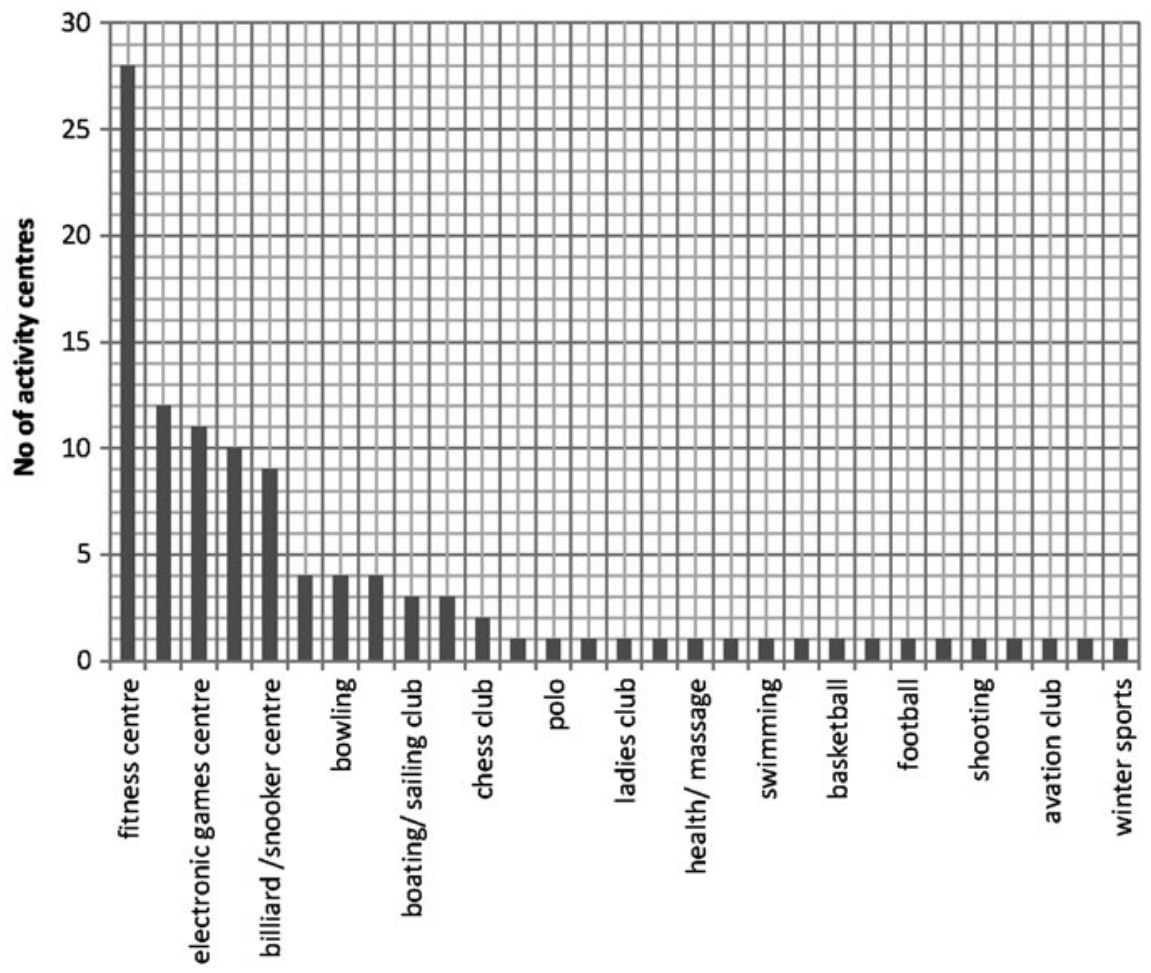

Figure 5. Typical Dubai recreational activities (Dubai Municipal). 
production processes" (Corner, 2003, p. 63) is however questionable. Particularly when viewed within the context of a society where "No real effort is made to resolve social problems, address concerns of the lower class, or try to make the urban environment more liveable" (Elsheshtawy, 2004, p. 172).

\section{Cultural Crisis}

One result of the massive amount of immigration that Dubai has experienced, since the discovery of oil in 1968, is the numeric dominance of expatriates. Comprising $83 \%$ of the total population, Dubai's expatriate population is proportionally one of the world's largest (Migration Information, 2005). This results in an unusual situation where the local population is numerically dwarfed by expatriates. The accelerated rate of development which has accompanied this extreme population growth has also been a response to diminishing oil reserves. Due to Dubai's perceived lack of naturally occurring drawcards it is generally regarded that the trapping of global investment and tourism will need to be artificially stimulated for the city to survive in the long term. As such Dubai constantly craves being the centre of attention; paranoid that its fading from view will herald its rapid demise. The zenith in this respect is the "Palm" and "The World" developments which brand whole areas for the city from the perspective of Google Earth.

It is within this context that landscape architects in Dubai, with only the minimum of concessions to Dubai's indigenous landscape and culture, have largely been content to rely on a pastiche aesthetic derived from both global and regional, and historical and contemporary sources. In this process the indigenous landscape and culture of "Arabia" often becomes a source of inspiration for the production of contemporary landscape design. The archetypal landscapes referenced are most commonly those of the desert, wadi, and the oasis. Traditional cultural landscapes that are frequently referenced are the souk and the Paradise garden. Significantly, this reference is generally form-driven as opposed to one that attempts to replicate the ecological and social functioning of these original landscapes. Elie Haddad, an architect with the Lebanese American University in Lebanon, defines this form of superficial regionalism as "pseudo regionalism" in which the designer pretends to "reconcile modernity and tradition by indiscriminately using elements from both repertoires without any genuine understanding of either" (Haddad, 2007, p. 44). This superficial situation results in Dubai landscape architecture's inability to sustain landscape architecture's "grand narrative of reconciling modernity to place" (Weller, 2006a, p. 75).

\section{The Potential of Landscape Urbanism to Increase Responsiveness to Local Culture in Dubai}

Within the context described the question becomes what Landscape Urbanism could offer landscape architecture in terms of establishing a deeper resonance with the local, albeit numerically marginalised, Emirati culture. Certainly, Landscape Urbanism theory offers no direct guidance as to conducting cross cultural design exercises, or indeed more generally reconciling development with "a sense of place" or local culture. This reflects the tone of Landscape Urbanism literature where the landscape is now typically an "accelerant," "matrix," and "continuous surface," something seemingly available for 
anything, anytime. Thus relieving "landscape of its traditional burden as culture's anchor in a world adrift..." (Wall in Weller, 2008, p. 254). Wall's rationale for this conception of urban landscape is indeed based on "new urban conditions of placelessness and the mobility of capital, goods and people," conditions seemingly at odds with landscape architecture's traditional desire for "groundedness, orientation and emplacement" (Weller, 2007, p. 29). Other Dutch landscape urbanists such as Bart Lootsma do however propose the method of datascaping which they believe could begin to articulate differences between regional locations. While this tool does not provide a guide for a cross cultural design exercise or for reconciling development with "place", it is the only aspect of Landscape Urbanism theory which is relevant to the complexities of practice in regional locations.

\section{Datascaping}

Landscape Urbanism theory claims to privilege an objective understanding of site forces, not the designer's own subjective artistic intuitions (Weller, 2006b, p. 67). This is driven, in part, by the analysis and design methodology of datascaping. As architect Bart Lootsma explains:

Datascapes are visual representations of all the measurable forces that may influence the work of the architect or even steer or regulate it. These influences may be planning and building regulations, technical and economic constraints, natural conditions such as wind and sun, or legislative measures such as minimum working conditions. (Lootsma, 1999, p. 270)

Datascaping is a methodology that features strongly in the design process of a number of Dutch landscape architects and architects including OMA, West 8 and MVRDV (Lootsma, 1999, p. 265) and can be seen as part of a larger landscape urbanist focus on the understanding of site forces as generating design.

Datascaping's promise of the removal of subjectivity from the design process has tended to polarise reactions to it. Winy Maas, principal of the design firm MVRDV, describes how, through datascaping, artistic intuition is replaced by "research" (Maas, 1998, p. 49). In this model, Maas articulates the notion that if enough data is "plugged in" and extrapolated then a form will "materialise" that is "beyond artistic intuition" (Maas, 1998, p. 49).

\section{Datascaping and Synthetic Regionalisation}

Of significance to this paper is that Lootsma proposes that datascaping will, in time, produce forms of "synthetic regionalisation" in response to data "gravity fields" that are specific to particular places (Lootsma, 1999, p. 270). Lootsma states that datascaping is concerned with "critical pragmatism" not "critical regionalism." As such where critical regionalism aspires to the "grand narrative of reconciling modernity to place" (Weller, 2007 , p. 40) and relies on interpretations of topography, climate, and light to achieve this reconciliation, critical pragmatism applies a much more utilitarian method of articulating a site's identity through close attention to a site's data. 
In the critique of globalisation as inimical to difference as found in the writings of Lootsma (1999), Zaera Polo (1994) and Maas (1998), it is proposed that, through attention to the abstract data of globalisation, globalisation's apparent enhancement of diversification will necessarily follow. In short, landscape urbanists are suggesting that globalisation can also enhance difference. For Maas, places are manifestly different and this difference is quite simply because of the basic data that lies behind their formal properties (Weller, 2007, p. 38).

\section{The Potential of Datascaping in Dubai to Articulate Regional Difference}

The question remains to what degree datascaping could assist a landscape urbanist in Dubai in producing landscape design which expresses regional difference. The technique of datascaping as a method for generating projects which articulate regional difference can be seen to have both potential possibilities and problems in Dubai.

The problems potentially arise from the fact that landscape architects working in Dubai often do not have the required information or data to make basic decisions, let alone to construct a datascaping design methodology. Dubai generally tends to be an unregulated building environment and as such the planning, building, and legislative regulations found in Lootsma's Holland (1999) often do not exist in Dubai; indeed what regulatory data that is available in Dubai often derives from internationally accepted standards and thus cannot be expected to contribute to the differentiation of Dubai. To compound this issue further, the amount of data available to a landscape architect in Dubai is also considerably less than what would be available to an architect.

The possibilities spring from Dubai's often extreme data which relates to climate, technical constraints, economics and demographics, which would presumably assist in generating unique landscape urbanist design outcomes if given due importance in the design process. Indeed, close attention to technical data such as irrigation requirements could herald, in contrast to the existing Dubai Municipality parks, a vastly reconfigured, xerophytic form of open space.

A problem remains however, even if all the required data was readily available, it would be unlikely to ever completely prepare a landscape urbanist in Dubai for engaging with the complex cultural, societal, and ultimately pragmatic issues such as one finds in Dubai. As Weller notes, "making form, and crafting its semiotic load, cannot be indefinitely deferred or completely conferred on to mechanisms beyond the author" (Weller, 2007, p. 39). Thus, while a privileging of site forces through datascaping can bring a designer closer to apprehending the aesthetic qualities of place, it cannot be regarded as a means by which the creative and necessarily subjective response to place can be deferred completely.

Take, for example, the aforementioned technical data regarding irrigation; even if a landscape urbanist in Dubai is cognizant of the extreme irrigation requirements of a palm tree (128 litres per day in summer), and turf (15 litres per square metre in summer) this data, in itself, will not objectively direct them towards a design. From a broader perspective this issue then needs to be then considered with respect to how much irrigated "green" landscape is required by the users of landscape either for active or passive recreational pursuits, or perhaps more importantly to meet Emirati and expatriate cultural expectations for greenery (Ouis, 2002), something that is very 
difficult to reduce to data alone. Any of the objectivity that Maas (1998, p. 49) describes in the design process very quickly becomes mired with a series of necessarily subjective decisions. A situation that in itself is not problematic, it is just not necessarily that different from an orthodox landscape architectural design process, and is unlikely to articulate regional differences to any greater degree. Indeed landscape architecture is also no stranger to site data. As Weller describes landscape architecture "has made site analysis data central to its design process and philosophy for the last three decades" (Weller, 2007, p. 39).

\section{Conclusion}

The principal conclusion of this paper is that a number of the tenets of Landscape Urbanism when applied to the various ecological, social and cultural crises experienced by landscape architecture in Dubai appear problematic. In this respect Landscape Urbanism could not be considered as a wholesale replacement for landscape architecture in Dubai. While a number of these tenets "privileging of site data" and a focus on "process", if employed in a reasoned manner, make some sense as a counterbalance to typical Dubai landscape architectural practice, the question remains as to what Landscape Urbanism offers a landscape urbanist in Dubai that is not already on offer as part of a well-practiced, ecological, socially and culturally aware form of landscape architecture. An attention to process, not merely form, is hardly new to landscape architecture, as is attention to site data (Weller, 2007, p. 39). While these shifts, proposed in Landscape Urbanism literature, may appear significant in relation to the current practice of Dubai landscape architecture, they are hardly momentous when considered in respect to the strands of more enlightened mainstream landscape architectural practice being conducted elsewhere.

Further to this a landscape urbanist in Dubai appears to be lacking the kind of tools which provide a bridge between theory and practice. While theories such as New Urbanism provide various tools (the Transect, Form Based Codes) by which the theory of New urbanism can be put into practice, Landscape Urbanism offers no such props for the practitioner in Dubai; leaving them to largely interpret how theory should be actioned. This is particularly the case where Landscape Urbanism claims "infrastructure and buildings" (Weller, 2006b, p. 67) as being within of its sphere of disciplinary influence. Landscape Urbanism literature offers very little to a landscape urbanist in Dubai as to how they would engage with these areas in practical terms. The risk of this general situation being perpetuated is that Landscape Urbanism may become more of a "planning and literary trope than a guide to physical design" (Dennis \& McIntosh, 2013, p. 51). Corner himself describes that the complex amalgam of Landscape Urbanism "is more than a singular image or style; it is an ethos, an attitude, a way of thinking and acting" (Corner, 2003, p. 58). While this may be the case it diminishes the potential of Landscape Urbanism in a place such as Dubai, where day to day practice very much dominates over theory. Ironically it is places such as Dubai which are experiencing rapid development that could most benefit from theory to informing practice.

Significantly for Landscape Urbanism to gain real traction in Dubai, landscape urbanists would need to be able to convince the existing hegemony of clients, architects and engineers that Landscape Urbanism offers a valid, reproducible method for 
reframing development. As Andres Duany describes in general terms "theory must be simple enough to be administered by a bureaucracy that is accustomed to the robotic protocols of Euclidean zoning. A theory that is not operational and cannot be widely applied does not respond to the scale of the current crises" (Duany, 2013, p. 117). This situation becomes compounded in the Middle East generally where the municipalities of most Arab cities "do not have the institutional structures, the human resources, and the technical experience which are required for the successful implementation" of complex master plans (Bianca, 2000, p. 198). While the common thought is that Landscape Urbanism can be the "solvent which breaks down the barriers" between the various disciplines (Thompson, 2011, p. 10) involved in urban design, this will only happen if they can be convinced of the veracity and applicability of the theory; and if the disciplinary land grabs which Landscape Urbanism has made can be substantiated in both theoretical and practical terms. If this does not occur then Landscape Urbanism will quickly fall prey to the similar tendency of landscape architecture to "claim the rights to everything but actually do very little" (Weller, 2006b, p. 71).

While Dubai is often viewed by the West as being a "fantasy world in the desert" (Davis, 2007, p. 63) many countries within the region look to Dubai as a city model that can be replicated or at least responded to. It is within this context that the practice of landscape architecture in Dubai, in conjunction with emerging theory, requires critical attention from the academy goal to which this paper has been directed.

\section{Acknowledgements}

First and foremost I would like to thank the generous and insightful reviewer who painstakingly reviewed a number of the previous drafts of this paper. Thanks also to Professor Richard Weller who supervised the related PhD study, Landscape Research editor Ian Thompson for his support, and Ross Bolleter and Jill Penter for copy editing various drafts of this paper.

\section{Notes}

1. The exact definition of these terms "city, landscape and ecology" are not stated in the paper cited. For the purposes of this paper, "city" will refer to areas of urban form, "landscape" to public open space , agricultural, semi natural or natural areas designed or otherwise and "ecology" to the relationship of organisms, human or otherwise, to their environment constructed or otherwise.

2. This may be in part due to our Western gaze to that indigenous landscape which doesn't allow us to see the nuances.

3. While there is conjecture about the meaning of the German word landschaft as it appears in Corner's writing, this paper will refer to Corner's interpretation as this pertains directly to the discussion of landschaft in this paper.

\section{References}

Abaza, M. (2011). Critical commentary. Cairo's downtown imagined: Dubaisation or Nostalgia? Urban Studies, 48, 1075-1087.

Andraos, A. (2007). Dubai's Island Urbanism: An archipelago of difference for the 21 st century? In S. Basar (Ed.), Vision plus money plus historical circumstance equals 'Cities From Zero' unapologetic expressions of new-found economic and therefore political-prowess in the 21st century (pp. 47-56). London: Architectural Association Publishing. 
Architectural Association Landscape Urbanism. (2013). AALU landscape urbanism. Retrieved March 4, 2013, from http://landscapeurbanism.aaschool.ac.uk/research

Basar, S. (2007a). Twelve ultimate critical steps to sudden urban success. In S. Basar (Ed.), Vision plus money plus historical circumstance equals 'Cities From Zero' unapologetic expressions of new- found economic and therefore political- prowess in the 21st century (pp. 73-95). London: Architectural Association Publishing.

Basar, S. (2007b). $\mathrm{V}+\mathrm{M}+\mathrm{HC}=\mathrm{CFZ}$ introduction. In S. Basar (Ed.), Vision plus money plus historical circumstance equals 'Cities From Zero' unapologetic expressions of new-found economic and therfore political-prowess in the 21st century (pp. 1-18). London: Architectural Association Publications.

Bianca, S. (2000). Urban form in the Arab world; past and present. London: Thames and Hudson.

Bolleter, J. (2009). Para-scape: Landscape architecture in Dubai. Journal of Landscape Architecture, 4, $28-41$.

Brookes, J. (1987). Gardens of paradise. London: Weidenfeld and Nicolson.

Bull, C., Weller, R., \& Bolleter, J. (2013). The urban issue. Landscape Architecture Australia, 1-82.

Congress for the New Urbanism. (2007). Charter of the new urbanism. In M. Larice \& E. MacDonald (Eds.), The urban design reader (pp. 308-311). Oxon: Routledge.

Corner, J. (1999). Eidetic operations and new landscapes recovering landscape: Essays in contemporary landscape architecture (pp. 153-170). New York, NY: Princeton Architectural Press.

Corner, J. (2003). Landscape Urbanism. In M. Mostafavi, \& C. Najle (Eds.), Landscape Urbanism a manual for the machinic landscape (pp. 58-62). London: Architectural Association.

Corner, J. (2006). Terra fluxus. In C. Waldheim (Ed.), The Landscape Urbanism reader (pp. 21-34). New York, NY: Princeton Architectural Press.

Crompton, J. (2005). The impact of parks on property values: Empirical evidence from the past two decades in the United States. Managing Leisure, 10, 203-218.

Davidson, C. (2008). Dubai. The vulnerability of success. New York, NY: Columbia University Press.

Davis, M. (2007). Fear and money in Dubai. Topos, 62-70.

Dennis, M., \& McIntosh, A. (2013). Landscape and the city. In A. Duany \& E. Talen (Eds.), Landscape Urbanism and its discontents: Dissimulating the sustainable city (pp. 35-56). Gabriola Island, BC: New Society Publishers.

Doherty, G. (2008). The landscape of Dubai's urbanism. Instant cities; emergent trends in architecture and urbanism in the Arab world (pp. 103-111). Amman: CSAAR.

Duany, A. (2013). A general theory of sustainable urbanism. In A. Duany \& E. Talen (Eds.), Landscape urbanism and its discontents: Dissimulating the sustainable city (pp. 115-123). Gabriola Island, BC: New Society Publishers.

Duany, A., \& Talen, E. (2013). Looking backward: Notes on a cultural episode. In A. Duany \& E. Talen (Eds.), Landscape urbanism and its discontents: Dissimulating the sustainable city (pp. 1-16). Gabriola Island, BC: New Society Publishers.

Dubai Municipality. (2001). Recreation centres in Dubai map recreation centres in Dubai map. Dubai: Dubai Municipality GIS Centre.

Dubai Municipality. (2003). Ras Al Khor Wildlife Sanctuary. 2008. Retrieved from http:/www.panda.org/ who_we_are/wwf_offices/united_arab_emirates/news/?20230/Ras-Al-Khor-Wildlife-Sanctuary

Dubai Municipality (Producer). (2004, 03 06). 4838 hectares of urban land to turn green by 2012. Dubai Municipality Portal. Retrieved from http://login.dm.gov.ae/wps/portal/SearchResultsEn?WCM_G...ect/ dmegov/DM+Internet+En/Home/Internet+News/NEWS223516/01/2008\%2012:35:26\%20PM

Elsheshtawy, Y. (2004). Redrawing boundaries: Dubai, an emerging global city. In Y. Elsheshtawy (Ed.), Planning Middle Eastern cities: An urban kaleidoscope in a globalizing world (pp. 164-187). Oxon: Routledge.

Fainstein, S. (2003). New directions in planning theory. In S. Campbell \& S. Fainstein (Eds.), Readings in planning theory (pp. 173-195). Malden: Blackwell.

Fishman, R. (2003). Urban utopias: Ebenezer Howard, Frank Lloyd Wright, and Le Corbusier. In S. Campbell \& S. Fainstein (Eds.), Readings in planning theory (pp. 21-60). Oxford: Blackwell.

Gallacher, D. (2007). Overgrazing their welcome. Zawaya, 1, 30-33.

Gallacher, D., \& Hill, J. (2007). Effects of camel grazing on density and species diversity of seedling emergence in the Dubai (UAE) inland desert. Journal of Arid Environments, 72, 853-860.

Guba, I., \& Glennie, K. (1998). Geology and geomorphology. In S. Ghazanfar, \& M. Fisher (Eds.), Vegetation of the Arabian Peninsula (pp. 39-62). Dordrecht: Kluwer Academic Publishers. 
Haddad, E. (2007). Critical regionalism and its discontents. Paper presented at the Regional Architecture and Identity in the Age of Globalization Conference, Dubai.

Harvey, D. (2002). Spaces of hope. Edinburgh: Cromwell Press.

Harvey, D. (2005). Spaces of global capitalism. London: Verso.

International Federation of Landscape Architects. IFLA Code of Ethics. (2008). Retrieved from http://www. iflaonline.org/resources/policy/pdf/ifla_ethics.pdf

Johnson, H., \& Hill, K. (2002). Introduction: Toward landscape realism. In H. Johnson, \& K. Hill (Eds.), Ecology and design: Frameworks for learning (pp. 1-28). Washington, DC: Island Press.

Kirchner, M., \& Rab, S. (2007). An Arabian night's fantasy, and that's ok. Al Manakh, 12, 18-22.

Koolhaas, R. (2007). Last chance. Al Manakh, 12, 7.

Kurschner, H. (1998). Biogeography and introduction to vegetation. In S. Ghazanfar \& M. Fisher (Eds.), Vegetation of the Arabian Peninsula (pp. 63-98). Dordrecht: Kluwer Academic Publishers.

Lootsma, B. (1999). Synthetic regionalization recovering landscape: Essays in contemporary landscape architecture (pp. 251-274). New York, NY: Princeton Architectural Press.

Maas, W. (1998). Datascape: The final extravaganza. Daidalos, 48-54.

Mafiwasta. (2007). Facts and figures. Mafiwasta for workers' rights in the United Arab Emirates. Retrieved from http://www.mafiwasta.com/UAE_statistics.html

Marsh, W. (2005). Landscape planning: Environmental applications. New Jersey, NJ: John Wiley \& Sons.

Migration Information. (2005). Metropolitan Dubai Area UAE Country and Metropolitan Stats in Brief (2005). Migration Information. Retrieved from http://www.migrationinformation.org/dataHub/GCMM/ Dubaidatasheet.pdf

Office for Metropolitan Architecture, Koolhaas, R., \& Mau, B. (1995). S, M, L, XL. New York, NY: Monacelli Press.

Ouis, P. (2002). Greening the emirates: The modern construction of nature in the United Arab Emirates. Cultural Geographies, 9, 334-347.

Parsons Harland Bartholomew. (1995). Structure plan for the Dubai urban area 1993-2012 (D. M. P. S. Department, Trans.). Dubai: Dubai Municipality Planning \& Survey Department.

Pulliam, H., \& Johnson, B. (2002). Ecology's new paradigm: What does it offer designers and planners. Ecology and design (pp. 51-84). Washington, DC: Island Press.

Shannon, K. (2008). Water urbanisms. Amsterdam: SUN.

Talen, E. (2013). The social apathy of Landscape Urbanism. In A. Duany \& E. Talen (Eds.), Landscape urbanism and its discontents: Dissimulating the sustainable city (pp. 105-114). Gabriola Island, BC: New Society Publishers.

Thompson, I. (2011). Ten tenets and six questions for Landscape Urbanism. Landscape Research, 37, 7-26.

Waldheim, C. (2002). Landscape urbanism. A Genealogy Praxis, 10-17.

Waldheim, C. (2006). Landscape as urbanism. In C. Waldheim (Ed.), The landscape urbanism reader (pp. 35-54). New York, NY: Princeton Architectural Press.

Waldheim, C. (2010). On landscape, ecology and other modifiers to urbanism. Topos, 20-24.

Waldheim, C., \& Berger, A. (2008). Logistics landscape. Landscape Journal, 27, 219-246.

Wall, A. (1999). Programming the urban surface recovering landscape: Essays in contemporary landscape architecture (pp. 233-250). New York City, NY: Princeton Architectural Press.

Weller, R. (2006a). An art of instrumentality: thinking through landscape urbanism. The landscape urbanism reader (pp. 69-86). New York City, NY: Princeton Architectural Press.

Weller, R. (2006b). Global theory, local practice. Kerb, 66-71.

Weller, R. (2007). Between hermeneutics and datascapes; a critical appreciation of emergent landscape design theory and praxis through the writings of James Corner 1990-2000. Landscape Review, 7, 3-44.

Weller, R. (2008). Landscape (Sub) urbanism in theory and practice. Landscape Journal, 27, 247-267.

Wells, M. (2008, 14.08). [Ecological Design in the Middle East].

Yang, P. P.-J. (2013). Landscape ecology and its urbanism. In A. Duany \& E. Talen (Eds.), Landscape urbanism and its discontents: Dissimulating the sustainable city (pp. 263-279). Gabriola Island, BC: New Society Publishers.

Zaera Polo, A. (1994). Order out of chaos: The material organization of advanced capitalism. Architectural Design Profile: The Periphery, 64, 24-29. 